\title{
A LUTA DAS MULHERES PELA IMPLEMENTAC̄̃O DE POLÍTICAS PÚBLICÁS DE PROTEÇÃO À VIDA PRIVADA E À INTIMIDADE
}

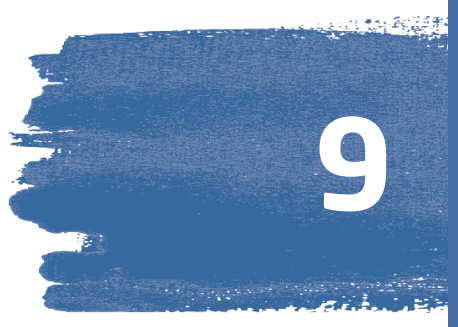

\author{
JUCÉLIA FÁTIMA SEIDLER ${ }^{58}$ \\ RIVA SOBRADO DE FREITAS 59
}

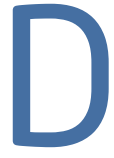

iante do progresso social, cultural, tecnológico e científico, somado à evolução dos meios de comunicação, verifica-se que aspectos inerentes à personalidade da pessoa humana ficam mais vulneráveis a interferências e intromissões alheias. A consequência de toda essa transformação é a discussão acerca da proteção da esfera privada das pessoas, sendo que os direitos relativos à personalidade, à vida privada e à intimidade merecem especial atenção legislativa e constitucional.

É possível encontrar definições conceituais diferenciadas e cada qual alinhada com as mais diversas correntes doutrinárias.

Na primeira parte deste trabalho, abordaremos a confusão conceitual entre vida privada e intimidade na doutrina e na jurisprudência brasileira, ilustrando com julgados e analisando as principais teorias desenvolvidas sobre o tema. Na segunda parte, analisaremos o modo como a doutrina brasileira trata os referidos direitos da personalidade (privacidade e intimidade) e as disposições legislativas

58 Mestranda no Curso de Direito Constitucional da Universidade do Oeste de Santa Catarina (UNOESC).

59 Professora e pesquisadora do programa de pesquisa, extensão e graduação em Direito da UNOESC. 
que servem de base para a sua defesa. Na terceira parte, teceremos as desigualdades sociais enfrentadas pelas mulheres e a busca pela implementação de políticas públicas para a defesa de seus direitos (vida privada e intimidade).

\section{CONFUSÃO CONCEITUAL: A VIDA PRIVADA E A INTIMIDADE}

As primeiras construções de distinção entre o direito à vida privada e o direito à intimidade remontam à jurisprudência francesa, que, em meados do século XIX, reconheceu a intimidade como uma esfera mais restrita que o direito à vida privada, na qual ninguém poderia penetrar sem expresso consentimento (Szaniawski, 2005, p. 322). ${ }^{60}$

Questiona-se, então, qual a importância prática dessa distinção, sobre a qual podemos tecer reflexões em pelo menos duas situações. A primeira diz respeito à privacidade de pessoas públicas (famosas), a qual colide com o princípio da liberdade de informação (Rescigno, 1974, p. 204-205) ${ }^{61}$. A vida privada dessas pessoas sofre intromissões legítimas, decorrentes do interesse público que envolve a sua posição perante a sociedade. No entanto, até mesmo essas pessoas têm direito a uma esfera reservada e inviolável, correspondente à intimidade (Cordeiro, 2004, p. 211-212) ${ }^{62}$.

60 Conforme explica o professor Elimar, foi no caso Rachel, julgado pelo Tribunal do Sena em 1858, que pela primeira vez se "reconheceu a existência de uma esfera íntima, ou de um círculo mais restrito do direito à vida privada (...), na qual ninguém pode penetrar sem expresso consentimento.".

61 Rescigno analisa a colisão entre os referidos princípios: "Con l'interesse dell'individuo alla protezione della sfera privata può venire in conflitto l'altrui libertà di manifestazione del pensiero, libertà che comprende l'apprezzamento, la valutazione, la critica de idee e fatti.".

62 Nesse sentido: "A esfera privada de tais políticos ou celebridades não desaparece: e, sobretudo, nunca ao ponto de atingir as esferas secreta e íntima. Mas pode ser fortemente suprimida, sem que se possa falar de atentado à privacidade.". 
Se considerássemos a vida privada e a intimidade como direitos únicos, sem distinções, estar-se-ia tolhendo das pessoas qualquer direito à privacidade.

A segunda situação se refere à positivação da vida privada e da intimidade enquanto direitos fundamentais autônomos no art. $5^{\circ}, \mathrm{X}$, da Carta Constitucional de 1988. Da forma como estão dispostos em nossa Constituição, os referidos direitos são normas de eficácia plena (Silva, 1968, p. 88 e ss). No momento em que se deixa de caracterizar o direito à intimidade ou se esta for tratada como sinônimo da vida privada, estar-se-á negando a efetividade a uma norma constitucional e por consequência não tutelando o referido direito.

No que se refere ao direito à vida privada e à intimidade, o judiciário brasileiro por vezes enfrenta conceitos e entendimentos divergentes: de um lado há a disposição constitucional feita pelo art. $5^{\circ}, \mathrm{X}$, da Constituição de 1988, que coloca lado a lado vida privada e intimidade, enquanto bens jurídicos distintos; de outro, tem-se a falta de uniformidade da doutrina, que em sua maioria trata a questão com imprecisão, passando a ideia de que vida privada e intimidade seriam conceitos sinônimos.

A definição positiva da noção "vida privada" é difícil. Como consequência dessa dificuldade, esta noção é mesmo por vezes caracterizada como sendo vaga, obscura e sem um verdadeiro conteúdo preciso (Druey, 1983, p. 9 c s; Wacks, 1980, p. 10 e ss).

Gomes Canotilho e Vital Moreira (1993, p. 181) escrevem que "não é fácil demarcar a linha divisória entre o campo da vida privada e familiar que goza de reserva de intimidade e o domínio mais ou menos aberto à publicidade (sendo diversas as teorias que pretendem fornecer o critério distintivo). Alguma doutrina distingue entre esfera pessoal intima (absolutamente protegida) e esfera privada simples (apenas relativamente protegida, podendo ter de ce- 
der em conflito com outro interesse ou bem público); mas a face desse preceito da Constituição da República Portuguesa parece não dar relevância a tal distinção. $\mathrm{O}$ critério constitucional deve talvez arrancar dos conceitos de "privacidade" e "dignidade humana", de modo a se definir um conceito de esfera privada de cada pessoa, culturalmente adequado à vida contemporânea. $\mathrm{O}$ âmbito normativo do direito fundamental à reserva da intimidade da vida privada e familiar deveria se delimitar, assim, como base num conceito de "vida privada" que tenha em conta a referência civilizacional sob três aspectos: o respeito aos comportamentos; o respeito ao anonimato; o respeito à vida em relação (Pinto, 2000, p. 153-204).

Tendo em vista o que se apresenta em virtude dessa confusão conceitual, a jurisprudência, apesar de na maioria das vezes fazer referência a ambos os termos, tende a tratá-los de forma unificada, como se a diferença entre ambos fosse meramente terminológica. No Brasil, não há consenso doutrinário no que diz respeito ao direito à vida privada e à intimidade. Essa verdadeira confusão conceitual, infelizmente, não se restringe ao campo doutrinário, apresentando-se, também, em diversas decisões judiciais proferidas por nossos tribunais.

DIREITO CIVIL E CONSTITUCIONAL. PEDIDO DE INDENIZAÇÃO POR DANOS MORAIS. LIBERDADE DE IMPRENSA. DIREITO À PRIVACIDADE E VIDA PRIVADA. AUTORIDADE PÚBLICA. INTERESSE COLETIVO NA APURAÇÃO DOS FATOS. CAUTELA DO ÓRGÃO DE IMPRENSA. NÃO CONFIGURAÇÃO DOS DANOS. HONORÁRIOS ADVOCATÍCIOS. FIXAÇÃO POR EQUIDADE (...).

1. O ordenamento constitucional, ao mesmo tempo em que assegura a inviolabilidade à honra, à vida privada (art. $\left.5^{\circ}, \mathrm{X}\right)$ e a proteção à imagem (art. $5^{\circ}$, XXVII), também prevê que 
a manifestação do pensamento, a expressão e a informação, sob qualquer forma, processo ou veículo, não sofrerão nenhuma restrição (art. 220).

2. Se, por um lado, a liberdade de informação deve limitarse frente ao direito dos particulares de terem sua vida privada e imagem preservados do conhecimento coletivo, por outro lado, o direito à intimidade também deve ser sopesado no caso de personagens públicos, como artistas, políticos e servidores, onde a exposição à mídia decorre diretamente da atenção que suas atividades despertam na sociedade (...) (Distrito Federal. TJDFT, 2007) (grifo nosso).

Pelo exposto, percebe-se a tendência a se tratar o direito à vida privada e à intimidade de forma unificada, sobretudo em dois momentos. O primeiro momento está consubstanciado no primeiro ponto em destaque, no qual se concebe que à garantia constitucional da liberdade de expressão e de informação se contrapõe a inviolabilidade da vida privada, da honra e da imagem. Pelo fato de não se ter incluído a intimidade ao lado da vida privada e dos demais bens jurídicos constitucionalmente invioláveis, pode-se denotar uma "tendente" intenção do órgão julgador de tratar os referidos conceitos indistintamente. Essa "tendência" explicitada pelo julgador está confirmada no trecho grifado da decisão acima elencada, na qual os termos vida privada e intimidade são utilizados como sinônimos.

A referida tendência de unificação pode ainda ser identificada em outra decisão do Tribunal de Justiça do Distrito Federal, na qual a diferença entre intimidade e privacidade (cujos termos foram utilizados para substituir "a vida privada”) restringe-se à terminologia, tendo em vista a nítida percepção de que ambos são tratados do mesmo modo, senão vejamos a ementa: 
RECLAMAÇÃO. MINISTÉRIO PÚBLICO. INTERCEPTAÇÃO TELEFÔNICA. DIREITO À INTIMIDADE E À PRIVACIDADE. CARÁTER RELATIVO. INTERESSE PÚBLICO. INVESTIGAÇÕES POLICIAIS. ELUCIDAÇÃO DE ESTELIONATO. PROPORCIONALIDADE. I. O DIREITO À INTIMIDADE E À PRIVACIDADE NÃO POSSUEM CARÁTER ABSOLUTO. CEDE ESPAÇO AO INTERESSE DA SOCIEDADE [...] (DISTRITO FEDERAL. TJDFT, 2009).

Pelo acima exposto, as razões de se conceber o âmbito privado da pessoa como uma série de esferas concêntricas - as quais quanto mais restritas deveriam ser mais protegidas -, seria oferecer às pessoas um núcleo mínimo de proteção. Esse núcleo absolutamente inviolável seria a esfera íntima ou a intimidade (Sampaio, 1998, p. 357; Szaniawski, 2005, p. 256).

$\mathrm{O}$ acórdão acima iguala privacidade e intimidade e afirma ainda que tanto um quanto o outro não possuem caráter absoluto, buscando afastar qualquer afirmação que procure distinguir os referidos termos. De acordo com esse julgado, privacidade e intimidade são (in)distintamente ponderáveis com o interesse da sociedade e devem ser analisados de acordo com o caso concreto apresentado.

Ainda que aos termos privacidade e intimidade sejam confundidos conceitualmente e, por vezes, sejam interpretados de diferentes formas, ambos são providos de proteção pelo nosso ordenamento jurídico.

\section{DIREITO À PRIVACIDADE E À INTIMIDADE}

Conforme exposto anteriormente, vida privada e intimidade são conceitos que, ao menos no campo do direito, carregam consigo uma grande controvérsia (Rescigno, 1974, p. 204). É difícil concei- 
tuá-los, é difícil conceber se são figuras autônomas ou interdependentes, assim como é difícil, e até mesmo desaconselhável na opinião de alguns (Dotti, 1980, p. 137), distinguir quais bens jurídicos realmente são alcançados nessas espécies.

Os aspectos da integridade moral dos direitos da personalidade tais como a honra, a imagem, a vida privada e a intimidade ficam, em face do progresso social, cultural, tecnológico e científico e com a evolução dos meios de comunicação, mais vulneráveis a interferências e intromissões alheias.

Em $A$ vida na sociedade da vigilância: a privacidade hoje, Stefano Rodotà destaca: “[...] ao lado da percepção, cada vez maior, dos riscos do progresso tecnológico, está a consciência da impossibilidade de deter tal progresso, mesmo se este não se apresenta mais com prognósticos somente positivos".

Tanto a intimidade quanto a vida privada possuem proteção jurídica em diversos dispositivos legais, seja no âmbito nacional ou no internacional. No plano internacional, podemos destacar a Declaração Universal dos Direitos do Homem, de 1948, ${ }^{63}$ em seu art. 12, que dispõe: "Ninguém será sujeito à interferência em sua vida privada, em sua família, em seu lar ou em sua correspondência, nem a ataque à sua honra e reputação. Todo ser humano tem direito à proteção da lei contra tais interferências ou ataques."

$\mathrm{O}$ art. $8^{\circ}$ da Convenção Europeia de Direitos do Homem ${ }^{64}$ (em vigor desde $1^{\circ}$ de junho de 2010) também elenca:

\section{Direito ao respeito pela vida privada e familiar}

1. Qualquer pessoa tem direito ao respeito da sua vida pri-

63 Documento eletrônico. Disponível em: <http://unesdoc.unesco.org/ images/0013/001394/139423por.pdf>. Acesso em: 21 mar. 2017.

64 Documento eletrônico. Disponível em: <http://www.echr.coe.int/Documents/Convention_POR. pdf>. Acesso em: 21 mar. 2017. 
vada e familiar, do seu domicílio e da sua correspondência.

2. Não pode haver ingerência da autoridade pública no exercício deste direito senão quando esta ingerência estiver prevista na lei e constituir uma providência que, numa sociedade democrática, seja necessária para a segurança nacional, para a segurança pública, para o bem-estar econômico do país, a defesa da ordem e a prevenção das infrações penais, a proteção da saúde ou da moral, ou a protecção dos direitos e das liberdades de terceiros.

No que concerne ao plano nacional, a Lei de Imprensa (lei n. 5.250/67) foi o primeiro instrumento legislativo a tutelar de forma expressa o direito à vida privada e à intimidade, nos termos do "art. 49 [...] $\$ 1^{\circ}$ Nos casos de calúnia e difamação, a prova da verdade, desde que admissível na forma dos arts. 20 e 21, excepcionada no prazo da contestação, excluirá a responsabilidade civil, salvo se o fato imputado, embora verdadeiro, diz respeito à vida privada do ofendido e a divulgação não foi motivada em razão de interesse público" (Brasil, 1967); e a referida lei assim o fez, tendo em vista a omissão do Código Civil de 1916, que nada disciplinou sobre os direitos da personalidade.

A Constituição de 1988, assim dispõe: "art. 5 [...] X - são invioláveis a intimidade, a vida privada, a honra e a imagem das pessoas, assegurado o direito à indenização pelo dano material ou moral decorrente de sua violação" (Brasil, 1988). Ainda que a intimidade e a vida privada tenham suas distinções, sua aplicação para uma ou para várias pessoas é a mesma, ou seja, enseja indenizações pelo dano moral e material decorrente de sua violação.

Nossa Constituição protege a privacidade (gênero) ao reconhecer como invioláveis a vida privada, a intimidade, a honra e a 
imagem das pessoas (espécies), assegurando o direito à indenização pelo dano material ou moral decorrente de sua violação. A esfera pessoal abrange as relações com o meio social sem que, no entanto, haja vontade ou interesse na divulgação; a esfera privada compreende os dados relativos a situações de maior proximidade emocional ("contextos relacionais específicos"), como as opções sexuais ou a orientação sexual do indivíduo (Wady, 2008) ${ }^{65}$.

A esfera íntima se refere ao modo de ser de cada pessoa, ao mundo intra-psíquico aliado aos sentimentos identitários próprios (autoestima, autoconfiança) e à sexualidade. Compreende a esfera confidencial e do segredo, referentes à intimidade. A vida privada é mais ampla do que a intimidade da pessoa. A vida privada é composta de informações em que somente a pessoa pode escolher se as divulga ou não. A intimidade diz respeito ao modo de ser da pessoa, à sua identidade (Andrighetto, 2013) ${ }^{66}$, que muitas vezes pode ser confundida com a vida privada. Em resumo, na vida privada há a intimidade da pessoa (Wady, 2008) ${ }^{67}$

Destaca Cohen (2012, p. 165-203) que a "garantia da privacidade é vista como algo necessário à afirmação das identidades individuais e à proteção dos indivíduos em relação às práticas e valores majoritários na comunidade em que estão inseridos".

Para Flávia Piovesan (2003, p. 165), “a privacidade é uma esfera de liberdade em que temos a possibilidade de escolher nossas pre-

65 Documento eletrônico. Disponível em: <https://lfg.jusbrasil.com.br/noticias/74728/qual-a-diferenca-entre-vida-privada-e-intimidade-ariane-fucci-wady>. Acesso em: 16 fev. 2017.

66 A identidade do ser humano e suas diferenças constituem-se princípios do pensamento. A tentativa de compreender biológica e socialmente a realidade das coisas e dos meios faz parte de uma preconcepção do processo de efetivação da identidade e da diferença. Identificar, portanto, significa reconhecer um objeto por meio da determinação de invariáveis, cujas características determinam a coisa na sua unidade e individualidade durante o tempo de sua existência.

67 Documento eletrônico. Disponível em: <https://lfg.jusbrasil.com.br/noticias/74728/qual-a-diferenca-entre-vida-privada-e-intimidade-ariane-fucci-wady . Acesso em: 16 fev. 2017. 
ferências em vários aspectos: música, estudo, amizades e sexualidade". Destaca ainda que, "a partir dessa constatação óbvia, de que essa esfera de liberdade pessoal também alcança à sexualidade, é que se tem trabalhado a discriminação por orientação sexual". A proteção da privacidade abarca a escolha no sentido das preferências sexuais. Essa proteção deve ser estendida sempre que um ato estatal, público, privado, judicial ou legislativo adentrar na esfera protegida da liberdade de escolha.

Dentre os aspectos implicados nessas dimensões, a sexualidade aparece como um dos mais polêmicos e de difícil progresso. Apesar das lutas cada vez mais visíveis e articuladas dos movimentos feministas, gays, lésbicos, transgêneros e de profissionais do sexo, ainda falta muito para a participação em igualdade de condições desses grupos na vida social; apesar da aprovação, aqui e ali, de legislação protetiva de certos direitos, ainda falta muito para a sua efetivação e sua expansão em domínios importantes. Muitos fatores concorrem para essa situação de privação de direitos e limitação de oportunidades, objeto de atenção de variadas perspectivas (Rios, 2006, p. 71-100).

Para Sarlet (2016, p. 445), embora exista quem no direito constitucional brasileiro, em face do texto constitucional, busque traçar distinções entre o direito à privacidade e o direito à intimidade, ambas por vezes se confundem, mas esclarece que o direito à privacidade trata de reserva sobre comportamentos e acontecimentos atinentes aos relacionamentos pessoais em geral, nela incluindo as relações comerciais e profissionais, e o direito à intimidade guardaria a proteção de uma esfera mais íntima da vida do indivíduo, a qual envolveria as relações familiares e amizades. $\mathrm{O}$ autor destaca, 
ainda, que tal distinção se torna difícil de sustentar, em virtude da fluidez entre as diversas esferas da vida privada (incluindo a intimidade), bem como a intimidade no âmbito de proteção mais amplo do direito à vida privada (privacidade).

"Dos direitos fundamentais que dizem respeito à proteção da dignidade e personalidade humanas, o direito à privacidade (ou vida privada) é um dos mais relevantes, embora nem sempre tenha sido contemplado nas constituições, ao menos, não expressamente" (Sarlet; Marinoni; Mitidiero, 2016, p. 445). Quanto à evolução constitucional brasileira, esse direito demorou um pouco para ser expressamente previsto. Somente na Constituição Federal de 1988, a proteção da vida privada e da intimidade foi objeto de reconhecimento.

Tais direitos, destaca Ingo Wolfgang Sarlet (2016, p. 442), "em especial à intimidade nem sempre são expressamente positivados nos textos constitucionais e internacionais, pois em geral a intimidade constitui uma dimensão (esfera) da privacidade". Embora ambas tenham sido elencadas no mesmo artigo e inciso da Constituição Federal, devem ser analisadas conjuntamente, "pois são esferas (níveis) do direito à vida privada”.

Ainda no plano dos direitos nacionais, o art. 21 do Código Civil Brasileiro (Brasil, 2002) dispõe: "A vida privada da pessoa natural é inviolável, e o juiz, a requerimento do interessado, adotará as providências necessárias para impedir ou fazer cessar ato contrário a esta norma".

Além disso, a natureza do problema da intimidade e da vida privada requer uma rápida modificação para que o direito seja aplicado de forma que possa assegurar que a eficácia aos direitos da personalidade seja protegida conforme elencados nos artigos mencionados, por serem invioláveis, apesar de a temática não ser tão explícita e conceituar mais claramente o que vem a ser intimidade e vida privada. 
O direito à vida privada não coloca em questão o direito de estar só e de ser deixado só, mas no sentido de não sofrer interferência estatal ou de terceiros no tocante aos aspectos da vida pessoal (afetiva, sexual etc.) e familiar.

Em causa, está o controle por parte do indivíduo quanto às informações que lhe dizem respeito a ele somente, informações de sua vida pessoal, individual. De outro modo, o direito à privacidade consiste num direito de ser deixado em paz no sentido de proteção de uma esfera da vida privada, na qual o indivíduo pode desenvolver a sua individualidade sem ser submetido a comportamentos socialmente esperados (Sarlet; Marinoni; Mitidiero, 2016, p. 445).

Quanto às dimensões da privacidade pessoal reconhecidas pela Suprema Corte, é claramente central no domínio da intimidade o "direito a ser deixado em paz" (de não sofrer intromissão ou vigilância sem motivo justo) e a "privacidade decisória" (não ser submetido à regulação ou controle indevido)". Ambas dizem respeito às intimidades da vida pessoal, ainda que suas contestações sejam divergentes, onde a primeira das dimensões é menos contestada que a segunda (Cohen, 2012, p. 165-203).

"O direito a ser deixado em paz dá ênfase à privacidade informacional - controle sobre a aquisição, posse e disseminação de informações sobre a pessoa, juntamente com o controle sobre o acesso ou a observação por parte de terceiros", independentemente se forem indivíduos privados ou pertencerem a organizações ou se se tratarem de autoridades públicas. "Os debates se dão antes quanto à extensão do que com respeito à própria ideia de nosso 'direito a sermos deixados em paz"' (Cohen, 2012, p. 173).

Contudo, somente o direito a ser deixado em paz não é suficientemente buscado pelas mulheres, exigindo como acréscimo à cons- 
trução de identidade de gênero e o empoderamento ${ }^{68}$ do próprio corpo incorporado às demais relações de poder de que estas têm direito e merecem vê-los respeitados. Nesse sentido destaca Betânia Diniz Gonçalves (2008, p. 35) que “a construção de conceito de identidade de gênero se dá no contexto social, de forma relacional, no qual semelhanças e diferenças são marcadas entre homens e mulheres para além do aspecto biológico".

A privacidade da nossa vida é formada por escolhas feitas por nós de modo que ninguém as pode violar, ou seja, os atos praticados podem não ser mais da nossa vida privada, mas que seja feita de vontade própria para que todos saibam; já a intimidade é a demonstração do modo de ser da pessoa, a sua personalidade, que muitas das vezes pode ser confundida com a privacidade da pessoa, na qual o significado de uma é o que precisa ser levado em conta para que tenhamos harmonia entre o convívio social e as particularidades de nossos atos.

Torna-se difícil romper com a interpretação funcionalista e com outras interpretações desgastadas da questão da privacidade sem descartar os princípios válidos protegidos pelos direitos à privacidade. As questões, relações e arranjos por nossos antepassados construídos para serem tidos como privados, "naturais" - e, portanto, para além da justiça - tornaram-se assuntos de debate público e luta política, principalmente quando os limites estão sendo redesenhados e os significados vieram a ser desestabilizados, forçandonos a repensar os direitos à privacidade de formas e maneiras que ampliem a liberdade e a igualdade, ao invés de restringi-las (Cohen, 2012, p. 165-203).

68 Empoderamento feminino é o ato de conceder o poder de participação social às mulheres, garantindo que possam estar cientes sobre a luta pelos seus direitos, como a total igualdade entre os gêneros. Disponível em: <https://www.significados.com.br/empoderamento-feminino/>. Acesso em: 13 abr. 2017. 
Embora exista uma forte conexão com os direitos à honra e à imagem, a privacidade e a intimidade dizem mais intensamente e melhor se vinculam à identidade e à integridade moral da pessoa humana. Muito embora possa haver, por exemplo, correlata ligação entre o sigilo das correspondências e das comunicações, dados pessoais - tendo em vista sua importância e autonomia em relação à autonomia e à vida privada não - há que se afastarem importantes conexões entre a privacidade e outros direitos fundamentais (Sarlet; Marinoni; Mitidiero, 2016, p. 443).

Considerando sua dupla dimensão, objetiva e subjetiva, o direito à privacidade opera, na condição de direito subjetivo, em primeira linha como direito de defesa, portanto, como direito a não intervenção estatal e de terceiros no âmbito de proteção do direito, assim como de liberdade pessoal, como o direito de não ser impedido de levar sua vida privada de acordo com seus projetos e perspectivas vitais. A perspectiva objetiva dos direitos à privacidade e à intimidade se insurgem como um dever de proteção estatal, num sentido de proteção da esfera das relações privadas, no que se refere à garantia das condições constitutivas da fruição da vida privada (Sarlet; Marinoni; Mitidiero, 2016, p. 446).

As inovações tecnológicas, entendidas desde as sofisticadas técnicas de vigilância até biotecnologias que podem penetrar no que antes fora concebido como áreas as mais privadas e impenetráveis como, por exemplo, o útero, os genes etc., trouxeram para as mulheres a preocupação com a importância da proteção da privacidade pessoal das inéditas possibilidades de intervenção. $\mathrm{O}$ avanço da política de identidade - independentemente da sua forma, que vai do multiculturalismo ao fundamentalismo religioso politicamente orientado, do feminismo e do movimento gay às políticas étnica, racial e nacionalista - serviu para evidenciar as 
contrariedades do que se prega sobre a privacidade e os direitos a ela inerentes (Cohen, 2012, p. 165-203).

$\mathrm{O}$ direito à privacidade, bem como os demais direitos pessoais, não pode ser ilimitado e/ou imune a restrições. Porém, a Constituição Federal, por não prever expressamente reserva legal, além de tratar como direitos invioláveis o direito à privacidade e à intimidade, atribuiu a eles um elevado grau de proteção, de tal modo que somente admite qualquer restrição quando justificada e necessária a assegurar a proteção de outros direitos fundamentais ou bens constitucionais relevantes.

Quanto à possibilidade de renúncia, há de se observar os contornos gerais do regime jurídico dos direitos pessoais, tendo em vista que a proteção da vida privada guarda relação com o próprio estilo de vida do individuo, de modo a admitir-se certa redução, mas jamais anulação dos níveis de proteção individual na esfera da privacidade e da intimidade.

Exposto à confusão conceitual entre os termos privacidade e intimidade e os direitos de proteção tanto no plano internacional quanto nacional, resta-nos destacar que as maiores vítimas do desrespeito à privacidade e à intimidade são as mulheres.

Cohen (2012, p. 170) destaca que um direito à privacidade pessoal constitucionalmente protegido é indispensável a qualquer concepção moderna de liberdade e que sem a liberdade reprodutiva, assegurada em parte por tal direito, as mulheres ficam privadas do bem para o qual os direitos à privacidade foram concebidos e cuja proteção deve ser assegurada para todos.

Quanto ao direito à privacidade da mulher, a autora acrescenta: Parece que estamos em face de diferentes formas daquilo que chamarei de um "paradoxo dos direitos à privacidade". Segundo o primeiro argumento, parece quixotesca a 
tentativa de corrigir os defeitos da privacidade doméstica por meio de mais privacidade: como pode o poder privado (sobre as mulheres) ser solapado por direitos à privacidade? Da perspectiva comunitarista, por outro lado, conceder autonomia decisória às mulheres em assuntos de família por meio dos direitos à privacidade é comprar a escolha individual ao preço da solidariedade comunitária. E há ainda uma terceira dimensão do "paradoxo da privacidade" que é apontada por críticos de ambos os lados: enquanto os direitos à privacidade pretendem ser os meios de proteger os indivíduos em relação ao poder do Estado, eles também reforçam as tendências desintegradoras, atomizadoras e niveladoras na sociedade moderna, expondo assim as pessoas a maior regulação por parte das agências estatais e, nesse processo, destruindo tanto a solidariedade da comunidade familiar como a autonomia do indivíduo (Cohen, 2012, p. 170).

As mais recentes inovações tecnológicas, que variam desde técnicas biotecnológicas até as áreas mais restritas da vida privada, trouxeram muitas preocupações no sentido de proteger a privacidade pessoal das mais variadas e possíveis intervenções. Dessa forma, as mulheres não esperaram o fim do milênio para reivindicar seus direitos e buscar junto aos órgãos estatais e às organizações não governamentais a proteção da privacidade e da intimidade e sobre elas decidirem sem intervenção estatal que ultrapasse os limites da esfera da vida privada. 


\section{A LUTA DAS MULHERES PELA IMPLEMENTAÇÃO DE POLÍTICAS PÚBLICAS DE PROTEÇÃO AOS SEUS DIREITOS À PRIVACIDADE E À INTIMIDADE}

As relações sociais estabelecidas em todas as esferas da sociedade tendem a ser marcadas por especificidades de gênero. $O$ termo "gênero" indica uma forma de construção cultural, uma criação social de ideias sobre os papéis adequados aos homens e às mulheres. A ideia de gênero procura desnaturalizar àquilo que é socialmente construído, evidenciando a existência de um poder desigualmente distribuído entre homens e mulheres, que coloca as mulheres em posição de inferioridade.

$\mathrm{O}$ conceito de gênero, ao enfatizar as relações sociais entre os sexos, permite a apreensão de desigualdades entre homens e mulheres, que envolvem um de seus componentes centrais, as desigualdades de poder (Safiotti, 1994; Scott, 1995 apud Fujiwara, 2002 apud Farah, 2004, p. 48). Nas sociedades ocidentais, marcadas também por outros 'sistemas de desigualdade', como apontado pela abordagem pós-estruturalista, é possível constatar que o padrão dominante nas identidades de gênero de adultos envolve uma situação de subordinação e de dominação das mulheres, tanto na esfera pública como na privada (Carvalho, 1998 apud Farah, 2004, p. 48).

Qualquer atitude que vise distorcer os direitos das mulheres no interior de suas relações sofre a violação dos direitos à privacidade $\mathrm{e}$ à intimidade, legalmente protegidos. Nesse sentido, destaca Cohen (2012, p. 178) que:

Qualquer tipo de associação íntima pode envolver poder e exploração. Os indivíduos precisam de proteção no interior da [relação de intimidade] e não apenas para a intimidade. Assim, enquanto a privacidade "de entidade" 
deve servir como escudo protetor para as frágeis relações comunicativas que constituem a intimidade, os direitos à privacidade individual devem servir como proteção para a integridade pessoal e corporal dos membros da "família”, no caso dessas relações virem a sofrer distorções ou se romperem.

Não é recente a luta das mulheres pela inserção nos espaços públicos e privados em igualdade de condições de trabalho, cujo intuito é diminuir (sem com hipocrisia dizer aqui erradicar) as relações de poder e de hierarquia salarial historicamente desiguais entre mulheres e homens. A busca da igualdade diz respeito, ainda, às diferentes orientações sexuais, na participação política, nas decisões quanto às suas composições familiares, quanto à vida privada e à intimidade, além da igualdade racial e étnica, e provar que tais diferenças são apenas uma expressão da diversidade humana e da divergência de oportunidades.

A política, através do direito e de sua formação institucionalizada por meio da opinião e da vontade, ou mesmo informalmente contextualizada com o mundo da vida racionalizado, deve buscar, em todos os âmbitos, um melhor viver para a sociedade.

Quando falamos de políticas públicas e, consequentemente, da intervenção do Estado para garantir que algumas minorias tenham acesso a uma vida digna, estamos fazendo referências ao processo de efetivação de direitos, que depende também da validação discursiva. A possibilidade de questionar os valores dominantes e os procedimentos que protegem as maiorias em detrimento das minorias nas esferas econômica e social da sociedade é a regra do discurso, encontrada na obra de Habermas (1983, p. 110), Consciência moral e agir comunicativo. 
Contudo, faz-se necessário argumentar que nenhuma atividade estatal pode extrapolar seus poderes inviabilizando direitos da personalidade. Cada ser humano deseja formar sua própria identidade e sobre ela poder tomar suas decisões. Tal poder nada mais é que a demonstração de autonomia decisória em respeito ao seu direito à privacidade e à intimidade que, assim como o direito à identidade, não prescrevem. Nesse sentido, Cohen acrescenta:

Quero argumentar que, quando entendidos adequadamente, os direitos à privacidade garantidores da autonomia decisória em certos assuntos pessoais não apenas a protegem como também o fazem com respeito à chance de cada indivíduo desenvolver, revisar e buscar sua própria concepção do bem e sua identidade. Permitam-me formular o padrão subjacente a esse aspecto da privacidade como o direito de não ter as necessidades constitutivas de sua identidade violadas ou submetidas à interferência do Estado ou de terceiros sem que, para tanto, haja razões de fato inevitáveis. Esse padrão milita contra a imposição a alguém de uma identidade que esse alguém não afirma e adota livremente. Em suma, ele protege o princípio da autenticidade. De fato, mesmo que as necessidades ligadas à identidade pessoal de alguns conflitem com a interpretação da maioria sobre os valores da comunidade, os direitos de privacidade pessoal os protegem - a menos que violem princípios morais universais, e apenas nesse caso. É por isso que os direitos pessoais à privacidade (juntamente com os diretos à comunicação, naturalmente) garantem o direito de ser diferente (Cohen, 2012, p. 189).

Os direitos pessoais à privacidade não prescrevem como devem ser as identidades; eles antes asseguram a todos os indivíduos as precondições para que desenvolvam identi- 
dades íntegras que possam considerar como suas. Por um lado, garantindo a todos igualmente personalidade jurídica e autonomia decisória, os direitos à privacidade protegem a demanda de cada indivíduo concreto, não importa quão diferente ou esquisito, a ser tratado como igual pelos membros da comunidade. Por outro lado, os direitos à privacidade blindam as dimensões pessoais da vida do indivíduo contra escrutínio ou interferência indevidos. Como tais, eles protegem os processos de autodesenvolvimento e autorrealização envolvidos na formação da identidade. O princípio que articula essa ideia na doutrina americana da privacidade é o princípio da integridade da personalidade (inviolate personality) (Cohen, 2012, p. 189-190).

As mulheres, ainda que incorporadas de forma passiva, como 'clientela atendida' nas iniciativas que incorporam as perspectivas do País. Os programas revelam um potencial de empowerment das mulheres, pois estas passam a ter condições de tomar decisões sobre seu próprio cotidiano, ainda que, inicialmente, na esfera privada. As mulheres atendidas não apenas recebem tratamento de saúde, mas têm acesso a informações que as capacitam a tomar decisões relativas à sua saúde, à sexualidade, à contracepção e ao planejamento familiar (Farah, 2004, p. 61).

As ações afirmativas configuram uma categoria de políticas públicas destinadas a promover a inclusão social, política e econômica de grupos fragilizados ou menos favorecidos. As políticas dessas ações afirmativas pressupõem a ocorrência de desigualdades fáticas parciais que afetam um grupo social determinado, impondo uma decisão política que, em tese, atenue ou diminua essas desigualdades. 
Segundo Ronald Dworkin (2000, p. 443), as medidas de ações afirmativas não se baseiam na ideia segundo a qual os grupos que recebem os benefícios imediatos têm direito definitivo ao tratamento jurídico diferenciado, “[...] mas apenas na hipótese estratégica de que ajudá-los agora é uma maneira eficaz de atacar um problema nacional".

As políticas públicas positivas em uma sociedade globalizada e com tantas desigualdades sociais se tornaram imprescindíveis para a manutenção ou a efetivação da democracia; isso é o que muitos especialistas acreditam. Porém, o que não podemos deixar de reconhecer é a atuação constante e expressiva de tais políticas desde os países de primeiro mundo (desenvolvidos) até, e principalmente, em países de terceiro mundo (subdesenvolvidos) (Ribeiro, 2012).

No Brasil, a luta das mulheres levou à formação do Plano Nacional de Políticas para as Mulheres, fruto do diálogo entre governo e sociedade civil e que desde 2003 (com reformas constantes) visa reforçar o princípio de que, em um Estado plenamente democrático, a condição da participação social, sobretudo das mulheres, é constitutiva de todas as fases do ciclo das políticas públicas (Brasil, 2013) ${ }^{69}$.

Atualmente com 114 páginas, com muitas atualizações desde 2003, o Plano Nacional de Políticas para as Mulheres, fruto de muita luta das mulheres para conquistar direitos iguais aos homens e, principalmente, vê-los respeitados, contempla:

A transversalidade permite abordar problemas multidimensionais e intersetoriais de forma combinada, dividir responsabilidades e superar a persistente "departamentalização" da política. $\mathrm{Na}$ medida em que considera todas as formas

69 Documento eletrônico. Disponível em: <http://www.compromissoeatitude.org.br/wp-content/ uploads/2012/08/SPM_PNPM_2013.pdf>. Acesso em: 19 mar. 2017. p. 10. 
de desigualdade, combina ações para as mulheres e para a igualdade de gênero e, dessa forma, permite o enfrentamento do problema por inteiro.

[...]

Para a transformação dos espaços cristalizados de opressão e invisibilidade das mulheres dentro do aparato estatal, faz-se necessário um novo jeito de fazer política pública: a transversalidade. A transversalidade das políticas de gênero é, ao mesmo tempo, um construto teórico e um conjunto de ações e de práticas políticas e governamentais.

$[\ldots]$

Por meio da gestão da transversalidade é possível a reorganização de todas as políticas públicas e das instituições para incorporar a perspectiva de gênero, de modo que a ação do Estado como um todo seja a base da política para as mulheres. Na elaboração de todas as políticas públicas, em todas as suas fases, deve ser perguntado: como é possível contribuir para sedimentar a igualdade de gênero? $\left(\right.$ Brasil, 2013) ${ }^{70}$.

Não há como negar que a vida das mulheres mudou; e foi, neste início de século, que mais acentuadamente se propagou a igualdade de sexos, o direito à própria identidade, à privacidade e à intimidade e vários outros direitos da personalidade, que progrediram graças às pressões feministas e outras classes chamadas de "minorias" e aos progressos tecnológicos, embora não se possa negar, que ainda haja muitas resistências e discriminações.

As mulheres buscaram o reconhecimento das diferenças com o intuito de formarem suas próprias identidades. "A identidade

70 Documento eletrônico. Disponível em: <http://www.compromissoeatitude.org.br/wp-content/ uploads/2012/08/SPM_PNPM_2013.pdf>. Acesso em: 19 mar. 2017. p. 10. 
do ser humano e suas diferenças constituem princípios do pensamento, numa tentativa de compreender biológica e socialmente a realidade das coisas e dos meios faz parte de uma pré-concepção do processo de efetivação da identidade e da diferença" (Andrighetto, 2013).

Por diversas razões, a distinção público/privado se tornou uma preocupação central dos teóricos políticos (Cohen, 2012, p. 165-203 - tradução livre) $)^{71}$. O debate sobre "privatização", centrado na relação entre o Estado e a economia de mercado, foi renovado pelos desenvolvimentos ocorridos no ex-bloco soviético. Por outro lado, assumiram uma nova urgência os debates sobre como conceituar e estabelecer os limites entre a privacidade pessoal e a regulação legal/política, o que se deveu em parte a certos desenvolvimentos tecnológicos e em parte ao surgimento de uma "política de identidade" crescentemente agressiva (Cohen, 2012, p. 165-203).

Uma autonomia privada bem protegida contribui para assegurar a geração de autonomia pública tanto quanto, reciprocamente, o exercício apropriado da autonomia pública ajuda a garantir a gênese da autonomia privada (Jürgen Habermas, Paradigms of law).

[Trata-se de] ... afirmar o juízo moral de que as mulheres têm direito a ser tratadas como indivíduos ao invés de sofrerem restrições em função de seu sexo, mas também [de afirmar] o juízo moral de que o grupo a que pertencem não pode mais ser relegado a uma posição inferior (Nadi-

71 Do original em inglês: "rethinking privacy: autonomy, identity, and the abortion controversy" (Cohen, 2012, p. 165-203), publicado na coletânea Public and private in thought and practice: perspectives on a grand dichotomy, organizada por Jeff Weintraub e Krishan Kumar (Chicago: The Chicago University Press, 1997). Direitos autorais concedidos por University of Chicago Press. Tradução de André Villalobos. Revisão da tradução por Flávia Biroli. 
ne Taub \& Wendy Williams, "Will equality require more than assimilation, accommodation, or separation from the existing social structure?") (Cohen, 2012, p. 165).

O que tem orientado as políticas públicas é a divisão entre a esfera pública e a privada. As mulheres são consideradas um recurso disponível de apoio às ações do Estado. As ações estatais e governamentais, ainda que não tenham como concepção alterar a desigualdade nas relações de gêneros, acabam por favorecer os homens, pois, embora não revele explicitamente sua intenção em desequilibrar essas relações, suas políticas públicas acabam reforçando as atuais relações e sua naturalização.

As políticas públicas para as mulheres têm avançado, ainda que muito lentamente, na perspectiva do diálogo e da construção coletiva com os movimentos de mulheres, feministas e demais movimentos sociais, buscando reverter lógicas desiguais presentes há séculos na sociedade.

Nesse novo cenário político, reivindicações históricas, como a construção de creches e o enfrentamento massivo à violência contra as mulheres, ganham força e concretude, por um lado; por outro, em um contexto mais amplo, as políticas públicas para as mulheres assumem significados distintos, ora indicando um campo de atividade, ora um propósito político, efetivando programas de ação com resultados específicos. As políticas orientam as ações do Estado a fim de combater problemas decorrentes de práticas assimétricas historicamente configuradas que inviabilizam o processo de participação social e política democrática e igualitária, de mulheres e homens (Nobre; Faria; Silveira, 2005, p. 9). 
Contudo, deve prevalecer no âmbito das políticas públicas o paradigma de que a responsabilidade deve ser compartilhada, não recaindo apenas sobre o organismo de políticas para as mulheres promover a igualdade de gênero, o qual não deve ser único e exclusivo, mas deve ser responsabilidade de todos os órgãos dos três níveis federativos e da sociedade civil.

\section{CONSIDERAÇÕES FINAIS}

Neste trabalho, buscou-se analisar os diversos conceitos e entendimentos jurisprudenciais e doutrinários relacionados à privacidade e à intimidade, bem como os direitos a serem invocados em busca de sua proteção e preservação, destinando um capítulo para tratar especificamente sobre esses temas e questões relacionadas às mulheres, as quais, ainda, por vários fatores sociais, culturais, econômicos etc. são as maiores vítimas e as que mais sofrem discriminações.

A privacidade é componente essencial da formação da pessoa. A definição do que é exposto ou não sobre alguém, do que se quer tornar público ou o que se quer esconder, ou a quem se deseja revelar algo, define a identidade desse indivíduo e suas fronteiras com os demais.

"A vida privada da pessoa natural é inviolável..." - acaba por ser muito menos um imperativo do que um elemento a ser sopesado dentre outros para que se verifique sua real extensão. A inviolabilidade é, tradicionalmente, atributo dos direitos da personalidade, ao lado de outros os quais compõem um perfil muito específico para este instituto, por estarem tão próximos à finalidade última do ordenamento jurídico, qual seja, a proteção da pessoa humana.

Na menção feita à "vida privada" no art. 21 do Código Civil Brasileiro de 2002, o direito encontra respaldo imediato na dispo- 
sição constitucional de proteção à vida privada, presente no art. $5^{\circ}$, X, da Constituição Federal de 1988, que, literalmente, protege não somente esta como também a intimidade e a imagem.

Evidenciou-se que as mulheres foram historicamente colocadas em posição de inferioridade em relação aos homens ou por questões culturais ou por ideologias, as quais buscaram por meio de organizações, uma movimentação a fim de reivindicar e forçar os órgãos estatais com o apoio de sociedade civis a implementar (ainda que de forma lenta, com muitas resistências masculinas e porque não dizer também femininas e com muitas restrições) políticas públicas de concessão de direitos e de combate à discriminação.

Denotou-se que o processo de constitucionalização e a busca pela efetividade dos direitos da mulher, principalmente os relacionadas à vida privada e à intimidade, e sua evolução dos tempos remotos à atualidade, é um tema extenso, cujo escopo deste trabalho não intenciona esgotar o assunto, mas contribuir para o enriquecimento do tema.

\section{REFERÊNCIAS}

ANDRIGHETTO, A. Direito das minorias: Proteção e reconhecimento. Revista Amicus Curiae. 2013. Disponível em: $<\mathrm{http} / / /$ periodicos.unesc. net/amicus/article/viewFile/1301/1238>. Acesso em: 13 abr. 2017.

BRASIL. Código civil Brasileiro. Lei 10.406/2002. Brasília, DF: Senado Federal, 2002. Disponível em: <http://www.planalto.gov.br/ccivil_03/ Constituicao/Constituicao.htm>. Acesso em: 8 fev. 2017.

BRASIL. Constituição da República Federativa do Brasil de 1988. Brasília, DF: Senado Federal, 1988. Disponível em: <http://www.planalto. gov.br/ccivil_03/Constituicao/Constituicao.htm>. Acesso em: 9 fev. 2017. 
BRASIL. Convenção Europeia de Direitos do Homem. Disponível em: $<$ http://www.echr.coe.int/Documents/Convention_POR.pdf $>$. Acesso em: 21 mar. 2017.

BRASIL. Declaração Universal dos Direitos do Homem. Disponível em: <http://unesdoc.unesco.org/images/0013/001394/139423por.pdf>. Acesso em: 21 mar. 2017.

BRASIL. Lei n. 5.250, de 9 de fevereiro de 1967. Disponível em: <http:// www.planalto.gov.br/ccivil_03/Leis/L5250.htm>. Acesso em: 20 fev. 2017.

BRASIL. Plano Nacional de Políticas Públicas para as Mulheres - 20132015. Disponível em: <http://www.compromissoeatitude.org.br/wpcontent/ uploads/2012/08/SPM_PNPM_2013.pdf>. Acesso em: 19 mar. 2017.

CANOTILHO, G.; MOREIRA, V. Constituição da República Portuguesa anotada. Coimbra. 1993.

CARLIN, V. I. A face feminina do direito e da justiça. Florianópolis: OAB/SC Editora, 2006.

CASTELLS, M. O poder da identidade. 6. ed. São Paulo: Paz e Terra. 2008.

CASTELLS, M. O poder da identidade. A era da informação: economia, sociedade e cultura. São Paulo: Paz e Terra, v. 2, 1999.

COHEN, J. L. Repensando a privacidade: autonomia, identidade e a controvérsia sobre o aborto. Revista Brasileira Ciência Política, n. 7. Brasília jan./abril. 2012. p. 165-203.

CORDEIRO, A. M. Tratado de Direito Civil Português: parte geral Pessoas. v. 1, t. III, Lisboa: Almedina, 2004.

DISTRITO FEDERAL. Tribunal de Justiça do Distrito Federal e Territórios. Apelação Cível n. 2003011114843-3. 2a Turma Cível. Relator: des. J. J. Costa Carvalho. Brasília, 14 de março de 2007. 
DISTRITO FEDERAL. Tribunal de Justiça do Distrito Federal e Territórios. Reclamação n. 001203511.2009.807.0000. TJ-DF - RCL: RCL 120351120098070000 DF 0012035-11.2009.807.0000 - 1 ${ }^{\text {a }}$ Turma Criminal. Relatora: desa. Sandra de Santis. Brasília, 29/10/2009.

DOTTI, R. A. A liberdade e o direito à intimidade. SENADO FEDERAL, Revista de informação legislativa. a. 17, n. 66. Brasília, 1980.

DRUY, J. N. Privat-Geheimsphre was liegt drin? Zdrich: FS Frank Mischer. 1983.

DWORKIN, R. Uma questão de princípio. Tradução Luís Carlos Borges. São Paulo: Martins Fontes, 2000.

FARAH, M. F. S. Gênero e políticas públicas. Estudos Feministas, Florianópolis, 12 (1): 47-71, jan.-abr./2004.

GONÇALVES, B. D. Identidade feminina e a inserção no mundo do poder. Curitiba: Juruá, 2008.

HABERMAS, J. Consciência moral e agir comunicativo. Rio de Janeiro: Tempo Brasileiro, 1983 A.

LORENZETTO, B. M. Direito e diferença: considerações constitucionais sobre o direito à identidade. Revista de Estudos Constitucionais, Hermenêutica e Teoria do Direito. Unisinos, 2012.

NOBRE, M.; FARIA, N.; SILVEIRA, M. L. Feminismo e a luta das mulheres. SOF: São Paulo, 2005.

PINTO, P. C. C. da M. “A protecção da vida privada e a Constituição. Boletim da Faculdade de Direito da Universidade de Coimbra 76 (2000): 153-204.

RESCIGNO, P. Manuale del diritto privato italiano. Napoli: Jovene Editore, 1974. 
RIBEIRO. J. S. da P. Políticas públicas e direitos humanos em Jürgen Habermas. Marília, SP. 2012.

RIOS, R. R. Para um direito democrático da sexualidade. Horizontes antropológicos. v. 12. n. 26. Porto Alegre. July/Dec. 2006.

RIOS, R. R. PIOVESAN, F. A discriminação por gênero e por orientação sexual. Seminário Internacional - As minorias e o direito Série Cadernos do CEJ; v. 24. Brasília: CJF, 2003.

SAMPAIO, J. A. L. Direito à intimidade e à vida privada: uma visão jurídica da sexualidade da família, da comunicação e informações pessoais, da vida e da morte. Belo Horizonte: Del Rey, 1998.

SARLET, I. W.; MARINONI, L. G.; MITIDIERO, D. Curso de Direito Constitucional. 5. ed. (rev. e atual.) Porto Alegre e Curitiba: Saraiva. 2016

SILVA, J. A. da. Aplicabilidade das normas constitucionais. São Paulo: RT, 1968.

SZANIAWSKI, E. Direitos de personalidade e sua tutela. 2. ed. São Paulo. Revista dos Tribunais, 2005.

TAYLOR, C. Multiculturalismo. Lisboa, Portugal: Instituto Piaget, 1994.

WACKS, R. The protection of privacy. London, 1980, p. 10 e ss.

WADY, A. F. Qual a diferença entre vida privada e intimidade?

Disponível em: <https://lfg.jusbrasil.com.br/noticias/74728/qual-adiferenca-entre-vida-privada-e-intimidade-ariane-fucci-wady $>$. Acesso em: 16 fev. 2017. 